\section{A pattern of ocular morbidity of patients attending a clinic in Western Nepal}

\author{
Tuladhar S, ${ }^{*}$ Dhakal S ${ }^{2}$
}
${ }^{1}$ Department of Ophthalmology, Gandaki Medical College, Pokhara, Nepal and ${ }^{2}$ Department of Medicine, Western Regional Hospital, Pokhara, Nepal

*Correspondence to: Dr. Sarita Tuladhar, Department of Ophthalmology, Gandaki Medical College, Pokhara, Nepal, email: drtuladharsarita@yahoo.com, Tel. No.: (+977)-9841456286

\begin{abstract}
INTRODUCTION: Very few reports exist regarding the causes of ocular morbidity in Western Nepal. The study is performed to identify the causes of ocular morbidity in a clinic at Waling in Western Nepal.
\end{abstract}

MATERIALS AND METHODS: A retrospective study was done by reviewing the case records of all patients attending the eye clinic at Waling from August 2010 to August 2011.

RESULTS: The study included 915 patients, 617 were females (67.5\%), and 298 were males (32.5\%). Refractive error was the most common ocular morbidity accounting $26.8 \%$ followed by conjunctivitis $20.6 \%$, cataract $11.8 \%$, pterygium $6 \%$, chalazion/stye $4 \%$, ectropion/entropion $3.9 \%$, keratitis $3.8 \%$, dry eyes $2.8 \%$, and corneal opacities $2.3 \%$.

CONCLUSIONS: The study gives a picture and patterns of ocular disease in Western Nepal which will be helpful in planning \& management of ocular health programmes in Nepal.

KEYWORDS: Ocular diseases, Morbidities, Western Nepal

Article submitted 15 July. Reviewed 20 August. Author correction 29 August. Final version accepted 16 September 2012 


\section{INTRODUCTION}

Nepal is a developing country where health services are not accessible to majority of the population. Ophthalmology is one of the important specialties in medicare services. The number of ophthalmologist and the number of eye care service is not accessible to the entire population. So blindness and ocular disease is a major problem in Nepal ${ }^{1}$.

The important causes of blindness are cataract, followed by glaucoma and age-related macular degeneration. Pattern of blindness and visual impairment varies with age. According to Nepal blindness survey, prevalence of blindness is $0.8 \%$ and cataract is the most common cause of blindness followed by trachoma. ${ }^{1}$ Cataract is the most common cause of preventable blindness.

Not many studies have been done in Nepal regarding ocular morbidity. A hospital based study done in BPKIHS, showed cataract as the most common eye disease followed by refractive error, conjunctival disease, and glaucoma. ${ }^{2}$ Similar hospital based study done in Nepal Medical College, showed cataract, corneal diseases trauma and posterior segment disease as common ocular morbidities. ${ }^{3}$ Another study done in a satellite clinic in Bhaktapur, Nepal showed refractive errors as the most common ocular morbidity. ${ }^{4}$ The main objective of the study was to find out the current pattern of ocular morbidity in Western Nepal.

\section{MATERIALS AND METHODS}

This was a retrospective study conducted in all patients who attended the eye clinic at Waling from August 2010 to August 2011. The patient data were collected from the OPD register at the clinic. A total of 915 patients attended the eye clinic, which constituted the samples for the study.

Though our study was done in a private clinic, complete ophthalmological evaluation was done compared to other studies where slit lamp examination was not done to all patients. ${ }^{4,5}$ Visual acuity was evaluated using the Snellen's chart for the literates and illiterate E chart for the illerates and refraction was done if required. Patients were examined with slit lamp, direct and indirect ophthalmoscope for funduscopy, Schiotz tonometer for measuring intra ocular pressure. Cyclorefraction, Schirmer test and syringing were done if required. Torchlight was used to examine young children. Minor surgical procedures like young children. Minor surgical procedures like removal of foreign bodies, surgeries for chalazion, abscess, entropion, lid laceration were done under local anaesthesia. Patients requiring further investigations like glaucoma, retinal detachment, diabetes retinopathy and those requiring surgeries were referred to higher centers. All patients' data were entered and analyzed using Statistical package for Social Science version 16 (SPSS v 16).

\section{RESULTS}

A total of 915 patients were examined, out of which 617 (67.5\%) were females and 298 (32.5\%) were males. Patients examined were from all age groups, out of which maximum numbers of patients were females and maximum numbers of patients were in age group 11 to 20 years (Table 1). Refractive error was the most common ocular morbidity accounting $26.8 \%$ followed by conjunctivitis $(20.6 \%)$, cataract $(11.8 \%)$, pterygium $(6 \%)$, chalazion/stye $(4 \%)$, ectropion/entropion (3.9\%), keratitis (3.8\%), dry eyes $(2.8 \%)$, and corneal opacities $(2.3 \%)$ (Table 2$)$. Posterior segment diseases were diabetes retinopathy $(0.2 \%)$ and age related macular degeneration (1.1\%). Trauma related conditions were foreign bodies (1.3\%), subconjunctival haemorrhage $(0.8 \%)$, and eyelid injury $(0.3 \%)$. It was observed that refractive errors and conjunctivitis were seen more in the younger age groups, whereas cataract and posterior segment diseases were seen in the older age groups.

Table-1. Age and sex distribution of patients

\begin{tabular}{lcc}
\hline Age (years) & Male & Female \\
\cline { 2 - 3 } & $\mathrm{n}(\%)$ & $\mathrm{n}(\%)$ \\
\hline$\leq 10$ & $46(5.0)$ & $43(4.7)$ \\
$11-20$ & $84(9.2)$ & $187(20.4)$ \\
$21-30$ & $39(4.3)$ & $123(13.5)$ \\
$31-40$ & $36(3.9)$ & $85(9.3)$ \\
$41-50$ & $24(2.6)$ & $68(7.5)$ \\
$51-60$ & $25(2.7)$ & $36(3.9)$ \\
$\geq 60$ & $44(4.8)$ & $75(8.2)$ \\
Total & $298(32.5)$ & $617(67.5)$ \\
\hline
\end{tabular}

\section{DISCUSSION}

The study shows that females (67.5\%) had more eye problems than males $(32.5 \%)$. This could be due to easy access of the clinic which enables them to seek medical help without being dependent on their 
Table 2. Pattern of ocular disease

\begin{tabular}{lc}
\hline Diseases & $\mathrm{n}(\%)$ \\
\hline Refractive errors & $245(26.8)$ \\
Strabismus & $8(0.9)$ \\
Entropion/Ectropion & $36(3.9)$ \\
Stye/Chalazion & $37(4.0)$ \\
Conjunctivitis & $184(20.6)$ \\
Pterygium/pinguecula & $55(6.0)$ \\
Episcleritis & $16(1.7)$ \\
Dry eyes & $26(2.8)$ \\
Dacryocystitis & $12(1.3)$ \\
Keratitis & $35(3.8)$ \\
Corneal opacities & $21(2.3)$ \\
Cataract & $108(11.8)$ \\
Pseudophakia & $19(2.1)$ \\
Glaucoma and glaucoma & $15(1.6)$ \\
suspect & $2(0.2)$ \\
Diabetic retinopathy & $10(1.1)$ \\
Age related macular & $12(1.3)$ \\
degeneration & $7(0.8)$ \\
Trauma related Foreign body & $3(0.3)$ \\
Subconjunctival haemorrhage & $21(2.3)$ \\
Lid injury & $43(4.4)$ \\
NAD &
\end{tabular}

spouses or family members. Similar results showing a female preponderance was seen in the National Blindness Survey, ${ }^{1}$ which have showed that in the rural areas there was easy access to eye care services. Female preponderance was also seen in Gandaki Zone. ${ }^{6}$ Similar results were obtained in Lumbini Zone and Chetwan district of Nepal where women constituted $52 \%$ and $53 \%$ of the total enumerated and examined population, respectively. ${ }^{7}$ This is different from most hospital based studies where there is a male preponderance. ${ }^{8-10}$

Refractive error was the most common ocular morbidity accounting $26.8 \%$ followed by conjunctivitis $(20.6 \%)$, cataract $(11.8 \%)$, pterygium $(6 \%)$, chalazion/stye (4\%), ectropion/entropion (3.9\%), keratitis (3.8\%), dry eyes $(2.8 \%)$, and corneal opacities $(2.3 \%)$. Similar results were seen in a study performed in Bhaktapur where refractive error was the primary ocular morbidity accounting for $22.5 \%$, followed by cataract $(17.4 \%)$ and extra ocular diseases like, conjunctivitis (14.9\%), conjunctival degenerations (pterygium and pinguecula) (10.8\%). ${ }^{4}$ Similar results were also seen in a hospital based study done at Shree Birendra Hospital, ${ }^{8}$ where in all age group-except above 60 years-the most common ocular disease was conjunctival \& scleral disorders (23.7\%) followed by refractive error (18.8\%). In age group above 60 common disease $(66.0 \%)$ followed by conjunctiva \& scleral problem (10.4\%) and refractive error $(5.4 \%)$.

In a study performed in Gandaki Zone, ${ }^{6}$ cataract was the principal cause of blindness in $60.5 \%$. Other causes of visual impairment were refractive error (11.7\%), macular degeneration (8.7\%), and corneal opacities (8\%). In a study performed in a tertiary hospital in Bangladesh conjunctivitis was seen in $21.9 \%$, cataract in $9.2 \%$, refractory error in $15.2 \%$, headache in $11.1 \%$, dacryocystitis in $6.5 \%$ and blepharitis in $3.2 \% .^{5} \mathrm{~A}$ clinic based survey of several rural eye clinics in Cambodia showed that cataract, refractive error, anterior segment diseases, glaucoma were the common diseases seen in the community. ${ }^{11}$

In a study done in Ethopia, trachoma was found to be the leading cause of ocular morbidity (33.7\%) followed by refractive error (6.3\%) and nontrachomatous conjunctivitis (5.9\%).12 Similarly, in a study done in Nigeria, conjunctivitis was the most common ocular disease seen in $32.9 \%$, followed by cataract $(14.7 \%)$, ocular injuries $(12.8 \%)$ and refractive errors $(9.9 \%) .{ }^{13}$

\section{CONCLUSIONS}

In our study, females suffered from eye morbidities more than males. The most common ocular morbidity was refractive errors. Other morbidities found were cataract, pterygium, chalazion/stye, ectropion/entropion, keratitis, dry eyes and corneal apacities. The has given insight to understand the epidemiology of ocular diseases which will be helpful in planning \& management. Early detection of the diseases such as cataract \& glaucoma in this population will reduce the burden of blindness in Western, Nepal.

\section{REFERENCES}

1. Brilliant LB, Pokhrel RP, Grasset NC, et al. Blindness in Nepal. Bull World Health Organ 1985:63:375-386.

2. Panda A, Upahyay MP, Kumar N, Badhu B, Koirala S. Measuring the burden of ocular morbidity. Trop Doc 2002;32:227-230.

3. Rizyal A, Karmacharya PC, Koirala S: Profile of blindness in Nepal: a hospital based study. Nepal Med Coll J 2005;7:54-57).

4. Rizyal A, Shakya, Shrestha RK, Shrestha S. A study of ocular morbidity of patients attending a satellite clinic in Bhaktapur, Nepal. Nepal Med Coll J 2010;2:87-89.

5. Murad MAU, Alam MS, Miah AKMA, Akter MS, Kabir MH. Pattern of eye diseases in a tertiary hospital in a suburban area: A retrospective study. ORION Med J 2007;28:492-494. 
6. Sapkota YD, Pokhrel GP, Nirmalan PK, Dulal S, Maharjan IM, Prakash K. Prevalencec of blindness \& cataract surgery in Gandaki Zone, Nepal. Br J Ophthalmol 2006;90:411-416.

7. Sherchan A, Kandel RP, Sharma MK, Sapkota YD, Aghajanian J, Bassett KL. Blindness prevalence and cataract surgical coverage in Lumbini Zone and Chetwan District of Nepal. Br J Ophthalmol 2010;94:161-166.

8. Rajkarnikar S, Gurung A, Bist RR, Shrestha R, Shrestha SM. Pattern of ophthalmological diseases in the patients of Shree Birendra Hospital. Med J Shree Birendra Hosp 2010;9:30-37.

9. Badhu BP, Shrestha SP. Pattern of incurable blindness at BPKIHS. J Nepal Med Assoc 1997;37:370372.

10. RM KC, Ale JB, Singh SK. Pattern of blindness in Mechi: a hospital based study in Mechi Eye Care centre. J Nepal Med Assoc 1998;37:422-426.

11. Thomson I. A clinic based survey of blindness and eye diseases in Cambodia. Brit J Ophthalmol 1997; 81: 578580.

12. Mohammed Shaffi, Abebe Bejiga. Common eye diseases in children of rural community in Goro district, Central Ethiopia. Ethiop J Health Dev 2005;19:148-152.

13. Scott SC, Ajaiyeoba AL. Eye diseases in general outpatient clinic in Ibadan. Niger J Med 2003;12:76-80.

\section{Citing this article}

Tuladhar S, Dhakal S. A pattern of ocular morbidity of patients attending a clinic in Western Nepal. Int J Infect Microbiol 2012;1(1):34-37. 